\title{
ERRATUM
}

Jorge Zamora • Ernesto Lowy • Valentin Ruiz-del-Valle

Juan Moscoso • Juan Ignacio Serrano-Vela

Juan Rivero-de-Aguilar • Antonio Arnaiz-Villena

\section{Rhodopechys obsoleta (desert finch): a pale ancestor of greenfinches (Carduelis spp.) according to molecular phylogeny}

Published online: 13 April 2006

(C) Dt. Ornithologen-Gesellschaft e.V. 2006

\section{J Ornithol (2005) DOl:10.1007/s10336-005-0036-2}

Unfortunately, the publisher printed parts of the introduction and Fig. 1a with errors

The end of the second paragraph in the introduction was printed incorrectly in italics. Moreover, after the tribe Carduelini "Emphasis > " was inadvertently added to the text

Correct Fig. 1a, b is given here:

The online version of the original article can be found at http:// dx.doi.org/10.1007/s10336-005-0036-2

J. Zamora $\cdot$ E. Lowy $\cdot$ V. Ruiz-del-Valle $\cdot$ J. Moscoso

J. I. Serrano-Vela $\cdot$ J. Rivero-de-Aguilar $\cdot$ A. Arnaiz-Villena

Department of Immunology and Molecular Biology,

Universidad Complutense, Hospital 12 de Octubre,

San Carlos, 28041 Madrid, Spain

A. Arnaiz-Villena $(\square)$

Departamento de Microbiologìa I (Inmunonología),

Facultad de Medicina, Universidad Complutense,

28040 Madrid, Spain

E-mail: aarnaiz@med.ucm.es 

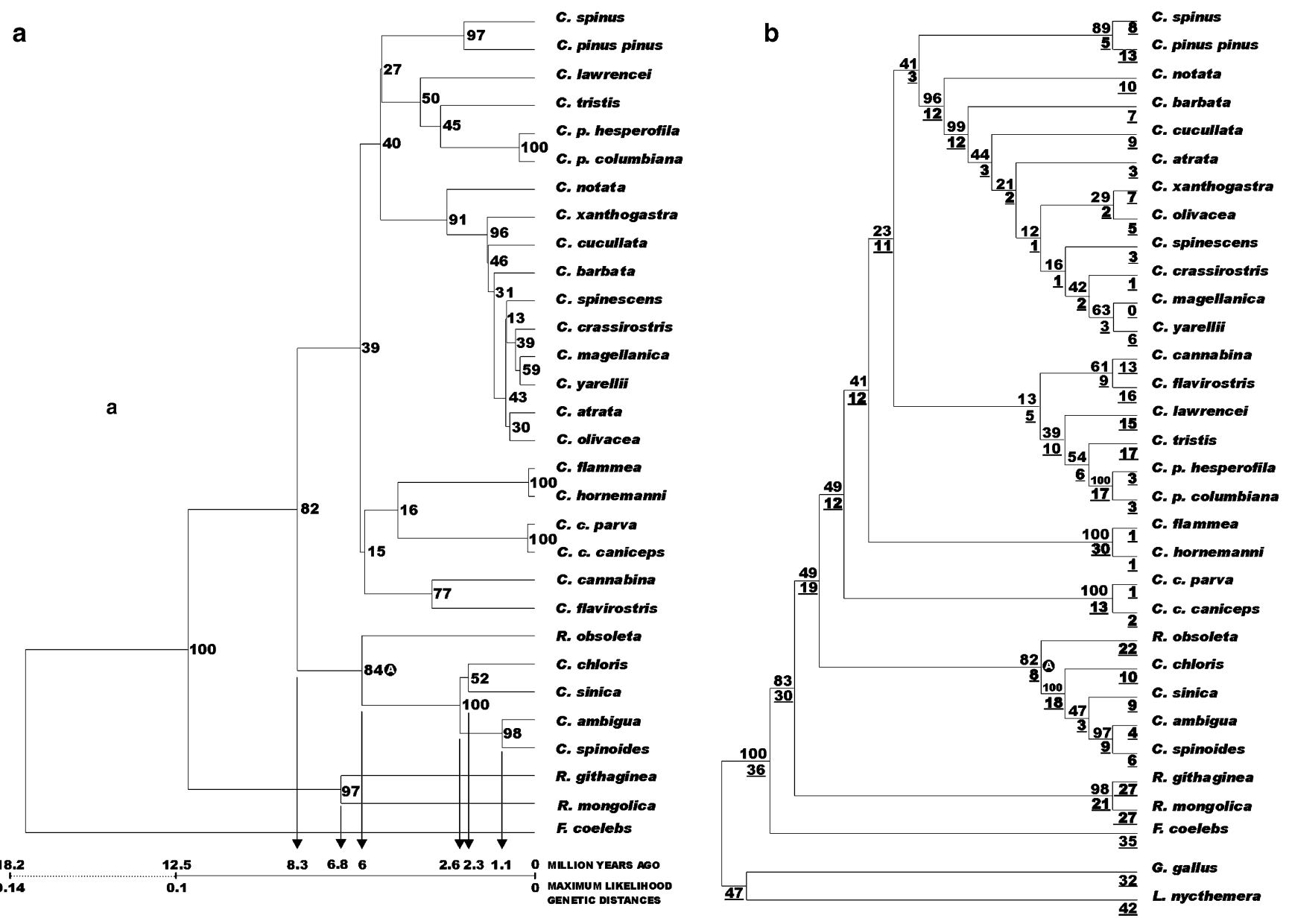

Fig. 1 a Maximum likelihood-based tree showing approximate calculations on the time of appearance of genera Carduelis and Rhodopechys lineages. This linearized tree was constructed by assuming that evolutionary rates between lineages may be different (Thorne et al. 1998). PARAMCLOCK PAUP command was used for tree building. Divergence times were estimated assuming an evolutionary rate of $0.8 \%$ substitutions per site and million years, found by Fleischer et al. (1998). This rate is based on the cyt b sequence divergence of Hawaiian drepanidines, and external geological calibration points. Groups of taxa are similar to those obtained in the parsimony (see Fig. 1b) and NJ with ML genetic distance dendrograms (tree not shown). Genus Carduelis speciation seems to have occurred during the Miocene and Pliocene epochs in both the Northern and Southern Hemispheres (Arnaiz-Villena et al. 1998). R. mongolica and $R$. githaginea cluster separately from $R$. obsoleta, that appears as the greenfinch ancestor. Thousand replication bootstrap values are depicted in the interior part of the nodes. ML-based tree scores: tree length $(1,000$ times $)=1,055$; ln Likelihood $=-4392.98019$ estimated transition/transversion ratio $=4.61 . \mathrm{ML}$ (1,000 times) genetic distances are depicted above the time scale (Million Years Ago). ML analysis settings were: two substitutions types; estimated transition/transversion ratio via ML; HKY85 model; empirical nucleotide frequencies; none assumed proportion of invariable sites and gamma distribution of rates at variable sites, divided in four categories as done by Yang (1994) for mitochondrial DNA sequences. b Parsimony tree. Branch length and 1,000 replication bootstrap values (Felsenstein 1985) are underlined below and above the branches, respectively. The addition of sequences was determined by the closest stepwise addition. TBR (Tree Bisection and Reconnection) branch swapping was set in order to increase the probability of finding the optimum trees. The scores for the parsimony tree are: tree length $=720$; consistency index $=0.497$; retention index $=0.664$. Chicken and Pheasant sequences (distant outgroups) were take from (Desjardins and Morais 1990) and (Kornegay et al. 1993), respectively 